\title{
Study on Construction Resource Optimization and Uncertain Risk of Urban Sewage Pipe Network
}

\author{
Xin $\mathrm{Li}^{1 *}$, Jian Huang ${ }^{2}$, Chunwei $\mathrm{Li}^{3}$, Ning $\mathrm{Luo}^{4}$, Wen Lei ${ }^{4}$, Haiyuan Fan ${ }^{5}$, Yuan Sun ${ }^{1}$, Weiqi Chen ${ }^{1}$ \\ ${ }^{1}$ Departmen of Building Intelligence, Jiangsu Vocational Institute of Architectural Technology, Xuzhou 221116, China \\ ${ }^{2}$ Xuzhou Hydraulic Engineering Construction Co., Ltd., Xuzhou 221006, China \\ ${ }^{3}$ Power China Eco-environmental Group Co., Ltd., Shenzhen 518102, China \\ ${ }^{4}$ Sinohydro Engineering Bureau 7 Co., Ltd., Chengdu 610081, China \\ ${ }^{5}$ Sinohydro Engineering Bureau 15 Co., Ltd., Xi'an, 710068, China \\ * Corresponding author, e-mail: songy3@hspharm.com
}

Received: 06 July 2021, Accepted: 24 November 2021, Published online: 21 December 2021

\begin{abstract}
With considering sewage pipe network upgrading projects in the "villages" in cities, the optimization of construction resources and the assessment of delay risks could be achieved. Based on the schedule-cost hypothetical theory, the mathematical model with constraint indicators was established to obtain the expression of optimal resource input, and conclude the method to analyze the schedule uncertainties. The analysis showed that cyclical footage of pipe could be regarded as a relatively fixed value, and the cost can be regarded as a function that depending on the number of working teams. The optimal number of teams and the optimal schedule occurred when the minimum total cost achieved. In the case of insufficient meteorological data, the Monte Carlo simulation method and uncertainty analysis method can be applied to assess the impact of rainfall on the total construction period, correspondingly the probability of such risk could be derived. The calculation showed that the risk of overdue completion varied significantly according to the construction starting time. It was necessary to take rainfall risk into consideration and make corresponding strategies and measures.
\end{abstract}

Keywords

hypothetical theory, pipe network construction, resource optimization, uncertainty, risk analysis

\section{Introduction}

With the acceleration of the urbanization in China, we are facing a serious situation of increasingly scarce water resource and deteriorating water environment, and the problem of black and smelly water in urban river channels is becoming more prominent. There are a number of reasons for black and smelly water, however, the main reason is the direct discharge of sewage and such sewage overflows in rainy days. According to the investigation, the "villages" in cities are crucial headstreams of black and smelly water, the regulation of sewage discharging problem in such "villages" is especially urgent. As an important part of pollution treatment, the construction schedule of pipe network projects directly affects the effectiveness of sewage treatment. On the one hand, the total number of "villages" in cities is huge, the population in such "villages" is of high density, there are hundreds of "villages" in cities in Guangzhou, Shenzhen and other places $[1,2]$, ten of millions people lived in these urban "villages". On the other hand, because of the narrow roadways, intricate underground pipelines and the highly intensive traffic flow in urban "villages" the construction of pipelines is characterized with tough working environment, multiple limiting factors and tense schedule. Therefore, it is necessary to analyze how to organize and complete treatment works in short time, how to effectively relieve various kinds of risks to optimize the engineering cost and resource input, thereby, to achieve the economic benefit and social benefit simultaneously.

At present, the research about the optimization of engineering and construction is mainly carried out from the perspective of cost and schedule. Through establishing an optimization model, the optimal schedule and cost could be determined. These researches mainly focused on the construction of roads, housing, etc. Gao and Chai [3] studied the optimal schedule of road construction based on the fuzzy mathematical method, Yang [4] studied the optimization of housing construction cost based on genetic 
algorithm, Ma and Zhang [5] established the optimized decision-making model for construction schedule based on improved genetic algorithm, Sarkar [6] constructed a resource optimization model which focus on schedule and cost through genetic algorithm Amiri et al. [7] studied the optimization of schedule and cost of multiple projects by the critical chain method, Heravi and Moridi [8] analyzed the resource optimization of repetitive construction projects. In terms of pipe network optimization, Safavi and Geranmehr [9] proposed a mathematical model for sewage pipe network optimization which included the material cost and construction cost under a given pipe network layout, Haghighi and Bakhshipour [10] proposed a sewage pipe network optimization model that applied adaptive genetic algorithm to deal with nonlinear and discrete problems, Tian et al. [11] applied discrete enumeration method to research the design and optimization of urban sewage transporting systems, Wang et al. [12] did the optimized calculation of water supply network through improved ant colony algorithm. Wols et al. [13] studied effects of climate conditions on the failures of drinking water distribution pipelines in Netherlands, Robles-Velasco et al. [14] studied an evolutionary fuzzy system to predict unexpected pipe failures in water supply networks, Robles-Velasco et al. [15] studied an artificial neural networks to forecast failures in water supply pipelines.

This article uses the sewage pipe network projects in urban "villages" that included in the integrated treatment project of water environment to study the optimization of construction resource and analyze the corresponding risks, sequentially, to provide references for project management and risk control of sewage pipe network projects in in urban "villages".

\section{Optimization model based on schedule-cost assumption}

\subsection{General assumption of schedule-cost}

For a project, the amount of resource input will directly affect the direct costs, and the construction timescale will affect the indirect costs. The direct cost includes labor cost, material cost, machine-shift cost, extra construction cost, etc., the indirect cost includes salaries of management staffs, asset royalties, insurance expense, etc. The sum of direct and indirect cost is the total cost of the project. For a specific project, the total cost generally decreases at first and then increases with the extension of the construction period [3]. The construction time becomes optimal when the total cost of a project comes to the lowest point, and the corresponding resource input at this time is also the optimal one.
Normally, the direct cost and the construction timescale are of quadratic relationship, and the indirect cost and construction timescale are of (positive) linear function [16, 17]. Supposing the project construction timescale is $t$, then the mathematical formula of direct cost can be expressed as:

$C D(t)=a t^{2}+b t+c$,

in which,

$C D(t)$ - Direct cost, ten thousand CNY;

$a, b, c$-Coefficients related to $t_{1}, t_{2}, C_{1}, C_{2}$ where,

$t_{1}$ - Minimal construction timescale, days;

$t_{2}$ - Normal construction timescale, days;

$C_{1}$ - Corresponding direct cost to $t_{1}$;

$C_{2}-$ Corresponding direct cost to $t_{2}$.

Generally, the direct cost increases as the construction timescale shortens and vice versa. When the construction timescale exceeds a certain period of time, it may cause the direct cost to increase. It could be approximately deduced that the cost at the inflection point is the normal cost, the corresponding construction timescale is the normal construction timescale. Therefore, we could get:

$C D^{\prime}\left(t_{2}\right)=0$.

Then $\left(t_{1}, C_{1}\right)$ and $\left(t_{2}, C_{2}\right)$ are substituted into the Eq. (1), respectively, afterwards, simultaneous equations that include Eq. (2) are established as below:

$$
\begin{aligned}
& a=\left(C_{1}-C_{2}\right) /\left(t_{1}-t_{2}\right)^{2}, \\
& b=2 t_{2}\left(C_{2}-C_{1}\right) /\left(t_{1}-t_{2}\right)^{2}, \\
& c=\left(C_{1} t_{2}^{2}-2 C_{2} t_{1} t_{2}+C_{2} t_{1}^{2}\right) /\left(t_{1}-t_{2}\right)^{2} .
\end{aligned}
$$

The mathematical formula of the indirect cost can be expressed as:

$$
C I(t)=\beta t,
$$

in which,

$C I(t)$ - Indirect cost, ten thousand CNY;

$\beta$ - Indirect cost rate.

Therefore,

$\beta=\left(C_{2}^{\prime}-C_{1}^{\prime}\right) /\left(t_{1}-t_{2}\right)$,

in which,

$C_{1}{ }^{\prime}$ - Indirect cost corresponds to $t_{1}$, ten thousand CNY; $C_{2}{ }^{\prime}$ - Indirect cost corresponds to $t_{2}$, ten thousand CNY.

Therefore, the total cost can be expressed as:

$$
C(t)=C I(t)+C D(t) \text {. }
$$




\begin{tabular}{|l|l|}
\hline \multicolumn{2}{|c|}{ The first phase, the second phase, and the third phase promote in accordarce with the flow of operations } \\
\hline $\begin{array}{l}\text { Preparation and start-up } \\
\text { phase (the first phase) }\end{array}$ \\
\begin{tabular}{|l|l|} 
(1) read bre and set-up, \\
roak $(\mathrm{A})$
\end{tabular} \\
$\begin{array}{l}\text { Every 100-200m is a loop footage (except } \\
\text { the first day, the rest of the time does } \\
\text { not account for the critical path) }\end{array}$
\end{tabular}

Fig. 1 Process phase division

\subsection{Mathematical model for resource optimization of the sewage pipe network}

The construction process of sewage pipe network mainly includes engineering surveying, breaking down of road surface, supporting, excavation, foundation constructing, pipe burying, well masoning, closed water test, concrete enclosing, soil backfilling, and road surface recovering. The above processes are ordered and classified as Fig. 1.

Process A is the construction preparation and start-up phase (the first phase), Processe B, C, and D are the critical phases (the second phase), and the Process E is the construction ending phase (the third phase), among which the second phase play a key role in determining the construction timescale. The first and third phases are organized and adjusted according to the implementation of second phase.

Assuming that the total length of pipe network of a project is $L$, the number of teams (number of working faces) is $x$, and the daily pipe footage that completed by each team (each working point) is $l_{d}$, then the construction timescale is:

$t=L /\left(l_{d} \cdot x\right)+1+1+1+8=L /\left(l_{d} \cdot x\right)+11$.

Substituting Eq. (1), Eq. (6), and Eq. (9) into Eq. (8), the mathematical model of total cost can be obtained as

$$
\begin{aligned}
C\left(x, l_{d}\right) & =a \cdot\left[L /\left(l_{d} \cdot x\right)+11\right]^{2} \\
& +(\beta+b) \cdot\left[L /\left(l_{d} \cdot x\right)+11\right]+c .
\end{aligned}
$$

According to Eq. (10), it could be concluded that the cost is related to the number of working faces and daily progress, that it is directly related to the number of teams and the daily pipe footage. Due to the restriction of the operating sites and the operating hours, the pipe footage driving cycle fluctuates within a relatively stable range, which can be considered as a relatively fixed value, therefore the cost can be regarded as a function related to the number of teams. When the pipe footage driving cycle remains unchanged, in order to minimize the total cost, the number of teams can be obtained by making $C^{\prime}\left(x, l_{d}\right)_{x}=0$. If $C^{\prime \prime}\left(x, l_{d}\right)_{x x}=0$, given this calculated number of teams, then this number of teams would be the optimal one and the corresponding construction timescale is the optimal one as well.

Then the derivative of Eq. (10) is calculated, and make $C^{\prime}\left(x, l_{d}\right)_{x}=0$, we could get:

$$
x=-2 a \cdot L /\left[l_{d} \cdot(22 a+b+\beta)\right] \text {. }
$$

From Eq. (11), it could be observed that the optimization objective is the number of working teams.

In order to ensure the construction timescale is within a reasonable range, the number of working teams which is directly related to the (total) reasonable engineering amount range $\left[L_{1}, L_{3}\right]$ of a single team must be constrained in a certain range, of which $L_{1}, L_{3}$ are related to the site environment, climatic conditions, processing equipment, etc. Therefore, this constraint can be established as follows:

$L_{1} \leq L / x \leq L_{3}$

where

$L_{1}$ - The minimum (reasonable) total amount of engineering for a single team, $\mathrm{m}$;

$L_{3}$ - The maximum (reasonable) total amount of engineering for a single team, $\mathrm{m}$.

Hence,

$L / L_{3} \leq x \leq L / L_{1}$.

For a project with pipe footage of $l_{d}$, assuming the maximum and minimum number of teams are $x_{1}, x_{3}$, respectively, the corresponding construction timescale are minimum and maximum ones respectively. Besides, assuming that the regular number of teams is $x_{2}$, the corresponding construction timescale is the regular one $t_{2}$. Therefore,

$$
\begin{aligned}
& x_{1}=L / L_{1}, \\
& x_{3}=L / L_{3} .
\end{aligned}
$$

Because the range of total (reasonable) engineering amount of a single team is $\left[L_{1}, L_{3}\right]$, it can be assumed that the regular engineering amount of a single team is the average value of the upper and lower limits of this range, which is, 
$L_{2}=\left(L_{1}+L_{3}\right) / 2$

where

$L_{2}$ - The regular total engineering amount of a single team, $\mathrm{m}$;

$x_{2}=2 L /\left(L_{1}+L_{3}\right)$.

Substituting Eq. (14) and Eq. (17) into Eq. (9) respectively, we could obtain $t_{1}, t_{2}$.

For daily direct cost, the function between the number of teams and the direct cost can be established:

$C_{d z}=x \cdot l_{d} \cdot C_{d 0}$,

where

$C_{d z}-$ The daily direct cost, ten thousand CNY;

$C_{d 0}$ - The direct cost per meter, ten thousand CNY.

According to Eq. (18), the maximum direct cost and regular direct cost which corresponding to the minimum construction timescale and the regular construction timescale respectively are as follow:

$C_{1}=x_{1} \cdot l_{d} \cdot C_{d 0} \cdot t_{1}$,

$C_{2}=x_{2} \cdot l_{d} \cdot C_{d 0} \cdot t_{2}$

For indirect cost, it can be expressed as:

$C I=C_{d j} \cdot t$,

where

$C_{d j}$ - Indirect cost occurred every day, ten thousand CNY.

Clearly, $\beta=C_{d j}$.

Substituting Eq. (19) and Eq. (20) into Eq. (3) and Eq. (4), respectively, then $a, b$ can be obtained, with substituting $a, b, \beta$ into Eq. (11), the optimal number of teams can be derived.

\section{Engineering application and analysis \\ 3.1 Project overview}

According to the "Three-Year Action Plan for Sewage Treatment in Guangzhou (2017-2019)", the task of this stage is to control the source of sewage, which includes the pollution treatment of 187 black and smelly watercourses and 85 involved "urban villages". Among these "urban villages", Dagang village, which is located in Baiyunhu Street, Baiyun District, has an area about 120 ha and total population about 28,448 . The projects mainly focused on pollution source control and sewage interception, including the renewal of sewage discharge system in the villages and municipality, through the construction of new sewage pipelines and reforming the combined sewage system into a divided one to separate rain and sewage, to achieve the goal of preventing the sewage directly discharging into the rivers. The projects could control the overflow pollution effectively, thereby eliminating the black and smelly water bodies. The engineering amount is shown in Table 1 .

\subsection{Optimization calculation and analysis}

After consulting the project managers and the on-site senior engineers, with taking the diversities of pipe diameters, materials, costs and the construction progress of pipelines in different locations into consideration, the average value would be used for calculation for convenience. Through analyzing the construction efficiency and the cost, the average daily cycle footage, the direct cost of each working surface and other parameters are determined (See Table 2 for details). Using the optimization model in Section 1, the optimal number of teams is 7.66 , which means 8 is the optimal number, and the corresponding optimal timescale is 118 days.

For the ease of verification and analysis, the corresponding timescale, cost and other parameters under different number of teams were calculated and listed in Table 3. It can be observed that the least total cost was achieved when the number of teams is 8 , which is consistent with the above

Table 1 Engineering amount of the sewage pipe network of Dagang

\begin{tabular}{|c|c|c|c|c|}
\hline & Item & Specification & Unit & Quantity \\
\hline 1 & UPVC drainage pipe & DN150 & $\mathrm{m}$ & 12,698 \\
\hline 2 & UPVC drainage pipe & DN200 & $\mathrm{m}$ & 9,004 \\
\hline 3 & $\begin{array}{l}\text { HDPE hollow winding } \\
\text { structure pipe }\end{array}$ & DN300 & $\mathrm{m}$ & 5,823 \\
\hline 4 & $\begin{array}{l}\text { Class II reinforced concrete } \\
\text { sewage pipe }\end{array}$ & $\mathrm{d} 300$ & $\mathrm{~m}$ & 1,831 \\
\hline 5 & $\begin{array}{l}\text { Class II reinforced concrete } \\
\text { sewage pipe }\end{array}$ & $\mathrm{d} 400$ & $\mathrm{~m}$ & 957 \\
\hline \multirow[t]{2}{*}{6} & $\begin{array}{l}\text { Class II reinforced concrete } \\
\text { sewage pipe }\end{array}$ & $\mathrm{d} 500$ & $\mathrm{~m}$ & 380 \\
\hline & & & Total & 30,693 \\
\hline
\end{tabular}

Table 2 Related cost parameters

\begin{tabular}{lccccc}
\hline Item & $\begin{array}{c}\text { Length } \\
\text { of pipe } \\
\text { network } \\
(\mathrm{m})\end{array}$ & $\begin{array}{c}\text { Pipe } \\
\text { footage } l_{d} \\
(\mathrm{~m} / \text { team } \cdot \text { day })\end{array}$ & $\begin{array}{c}\text { Cost per } \\
\text { meter } C_{d 0} \\
\text { (ten } \\
\text { thousand } \\
\text { yuan/m) }\end{array}$ & $\begin{array}{c}\text { Indirect } \\
\text { cost } C_{d j}(\text { ten } \\
\text { thousand } \\
\text { yuan/ }\end{array}$ & {$[L 1, L 3]$} \\
team·day) & \\
\hline $\begin{array}{l}\text { Para- } \\
\text { meter }\end{array}$ & 30,693 & 36 & 0.11 & 4.0 & {$[2,000$,} \\
\hline
\end{tabular}


Table 3 Related cost parameters for different number of teams

\begin{tabular}{|c|c|c|c|c|c|c|}
\hline $\begin{array}{l}\text { Number of } \\
\text { teams } x\end{array}$ & $\begin{array}{l}\text { Schedule } t \\
\text { (day) }\end{array}$ & $\begin{array}{c}\text { Indirect cost } C I \\
\text { (Ten thousand yuan) }\end{array}$ & $\begin{array}{c}\text { Direct cost } C D \\
\text { (Ten thousand yuan) }\end{array}$ & $\begin{array}{c}\text { Total cost } C \\
\text { (Ten thousand yuan) }\end{array}$ & $\begin{array}{c}\text { Proportion of } \\
\text { indirect cost }(\%)\end{array}$ & $\begin{array}{l}\text { Proportion of } \\
\text { direct cost (\%) }\end{array}$ \\
\hline 4 & 224 & 896.58 & $3,677.05$ & $4,573.63$ & 19.60 & 80.40 \\
\hline 5 & 182 & 726.07 & $3,599.60$ & $4,325.66$ & 16.79 & 83.21 \\
\hline 6 & 153 & 612.39 & $3,620.85$ & $4,233.24$ & 14.47 & 85.53 \\
\hline 7 & 133 & 531.19 & $3,671.74$ & $4,202.93$ & 12.64 & 87.36 \\
\hline 8 & 118 & 470.29 & $3,729.42$ & $4,199.71$ & 11.20 & 88.80 \\
\hline 9 & 106 & 422.93 & $3,785.86$ & $4,208.79$ & 10.05 & 89.95 \\
\hline 10 & 96 & 385.03 & $3,838.30$ & $4,223.33$ & 9.12 & 90.88 \\
\hline 11 & 89 & 354.03 & $3,886.02$ & $4,240.05$ & 8.35 & 91.65 \\
\hline 12 & 82 & 328.19 & $3,929.10$ & $4,257.30$ & 7.71 & 92.29 \\
\hline 13 & 77 & 306.33 & $3,967.91$ & $4,274.24$ & 7.17 & 92.83 \\
\hline 14 & 72 & 287.60 & $4,002.89$ & $4,290.49$ & 6.70 & 93.30 \\
\hline 15 & 68 & 271.36 & $4,044.72$ & $4,316.08$ & 6.29 & 93.71 \\
\hline
\end{tabular}

optimization result. Under the circumstance of which the number of teams is 8 , the indirect and direct cost account for approximately $11 \%$ and $89 \%$ of total cost, respectively. The proportion of indirect cost is negatively correlated with the number of teams, while the proportion of direct cost is the opposite. The lowest and highest proportion of indirect cost are about $6 \%$ and $20 \%$, respectively, and that of direct cost are about $80 \%$ and $94 \%$, respectively.

According to Table 3, the relationship curve between the number of teams and the timescale (number of teams - cost) is shown in Fig. 2. It can be observed that the construction timescale and total cost are strongly negatively correlated with the number of teams when the number of teams is less than the optimal number. The maximum reductions in timescale and total cost were 42 days and 2,479.7 thousand CNY, respectively. The construction timescale and total cost are moderately negatively correlated with the number of teams when the number of teams is greater than the optimal number. When the number of teams exceeds a certain number, the total cost tends to be constant.

\section{Risk analysis of schedule uncertainties}

\subsection{The research background of uncertainties}

Schedule uncertainties management can ensure the smooth progress of the implementation of each tasks in project and therefore plays an important role in project management [18]. Due to the underestimation of risks and uncertainties in practical project management, sometimes the projects could not be completed as scheduled. Therefore, it is of great theoretical significance and practical value to study the schedule risk management of engineering projects with uncertainties [19].

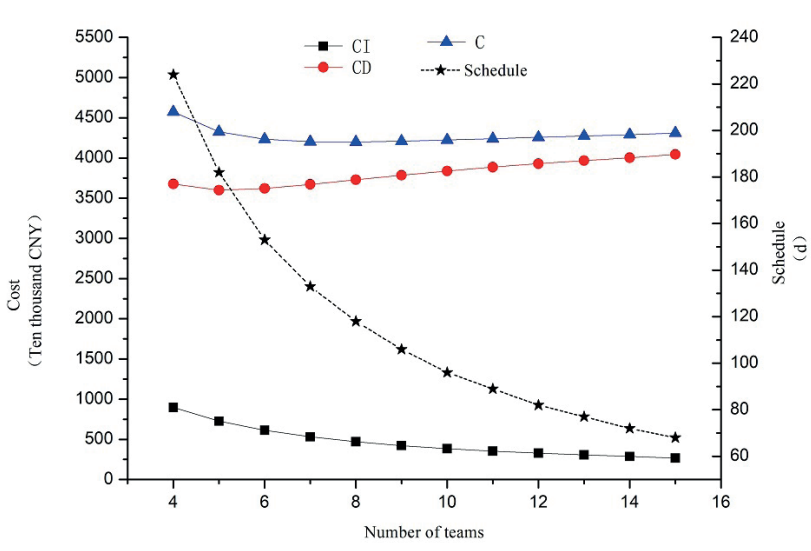

Fig. 2 Relationship between the number of teams, schedule and cost

For uncertainties analysis, scholars have conducted several in-depth studies, for instance, Wang et al. [20] carried out the construction cost risk analysis of dam filling projects using soil and stones on the basis of defining the construction cost risk; Tian et al. [21] proposed a Bayesian network-based risk analysis method for projects with existing pipelines in adjacent due to the complexity and uncertainty of construction with adjacent existing pipelines to take care of; Jiang et al. [22] established the project operational risk assessment model based on SPA cloud model in order to solve the problem of ambiguity and uncertainty existing in the recognition of risk factors during the operation process of hydraulic projects; Yuan et al. [23] proposed a security risk assessment method based on cloud model and uncertain AHP method in order to better solve the problems of ambiguity and randomness in the risk assessment of bridge construction. These studies mainly focused on the analysis and evaluation of uncertain risks in dam filling projects, railway construction projects, bridge 
construction projects and hydraulic projects, the research of theories and applications of risk control in urban sewage pipe network projects are insufficient, and the uncertainty analysis based on optimization of construction resources is particularly worthy discussing.

For probable events that beyond control, PietruchaUrbanik et al. [24] carried practical studies to establish a predictive model for the management of water supply system. The assessment of the effectiveness of management actions could be done through the predictive model, and the model provided a method to assess and predict the overall situation based on the statistical action data. Pietrucha-Urbanik et al. [25] studied the hazard assessment and risk management of water supply systems based on the functional safety concept, the methodologies and case studies presented in the paper will contribute to the decision-making process regarding to the safety and performance upgrading of water supply system. The above studies primarily focused on the risk management of water supply system, the risk management of the sewage pipe network construction needs to be further studied.

\subsection{Monte Carlo simulation of rainfall effect}

Monte Carlo Method, also known as simulated random sampling method or statistical experiment method, is a research method based on the principle of mathematical statistics. The general idea of Monte Carlo simulation is that, when solving problems with uncertain and random characteristics, the frequency of this event could be approximately treated as the probability of this event through random sampling method. Kwak and Ingall [26] believed that Monte Carlo simulation can predict the risk degree of project timescale and budget, so as to provide project managers with corresponding indexes. This method had been widely used in various risk studies [27].

Assuming the function relationship $Y=f\left(X_{1}, X_{2}, \ldots, X_{n}\right)$, the probability distribution of the independent variable $X_{1}, X_{2}, \ldots, X_{n}$ could be obtained according to the known conditions. Due to the fact that the practical problem is complicated and uncertain, $f\left(X_{1}, X_{2}, \ldots, X_{n}\right)$ is unknown or quite complicated, that makes it difficult to obtain the probability distribution expression of $Y$ by analytic method. Monte Carlo method generates $X_{1 i}, X_{2 i}, \ldots, X_{n i}$ ( $i$ is the number of time of simulation) by sampling the random variables, and then determines the value of $Y$, which is $y_{i}=f\left(X_{1 i}, X_{2 i}, \ldots, X_{n i}\right)$ according to the functional relationship $Y=f\left(X_{1}, X_{2}, \ldots, X_{n}\right)$. Through huge number of times of sampling the function $y$, a large number of sample data $\left(y_{1}, y_{2}, \ldots, y_{n}\right)$ is obtained. When the number of simulations is large enough, the approximate probability distribution of $Y$ can be acquired.

The foregoing optimization analysis of resource and cost is based on the consideration of absolute construction timescale. In practical engineering projects, external factors that affecting the construction timescale should also be take into consideration, which is mainly the rainfall. The degree of impact of rainfall is directly related to the rain distribution over the year. The rain distribution models mainly include lognormal distribution, exponential distribution, general extreme value distribution, Pearson III distribution, etc. [28]. According to the rainfall level, the construction schedule will be delayed by 1 day when the rainfall within 12 hours is greater than $5 \mathrm{~mm}$ or that within 24 hours is greater than $10 \mathrm{~mm}$. Monte Carlo theory could be used to analyze the weather impact on construction timescale in the absence of sufficient meteorological data.

Assuming that the rainfall within 12 hours on the $k$ day of the $i$ month is $m_{1 k}$, and that within 24 hours on the same day is $m_{2 k}$. Whether the construction timescale is affected by that day is recorded as $X_{k}$ (when $m_{1 k}>5$ or $m_{2 k}>10$ is recorded as 1 , otherwise it is recorded as 0 ), then a set of $X_{1}, X_{2}, \ldots, X_{n}$ is generated through the monthly rainfall data ( $n$ is the number of days in the month). Then, Monte Carlo method is applied to simulate the rainfall condition by $m$ times, and the simulation result is $X_{1}^{\prime}, X_{2}{ }^{\prime}, \ldots, X_{m}{ }^{\prime}$ (Table 4). Therefore, the probability of rainfall that would affect the construction timescale (hereinafter referred as the probability of rainfall impact) is $p_{i}=\sum_{j=1}^{m} X_{j}^{\prime} / m$, the number of days that construction timescale would be affected by rainfall is $n_{p i}$ (Fig. 3).

Table 4 Sample data under different rainfall

\begin{tabular}{lcccccccccc}
\hline August & 1st day & 2nd day & 3rd day & 4th day & 5th day & 6th day & 7th day & 8th day & 9th day & 10th day \\
\hline 08:00 to 20:00 (mm) & 62.2 & 0.0 & 23.6 & 14.5 & 0.0 & 0.0 & 0.0 & 0.0 & 0.0 & 0.0 \\
20:00 to 20:00 (mm) & 92.1 & 0.0 & 25.2 & 15.4 & 0.4 & 0.0 & 0.0 & 0.0 \\
$X_{k}$ (Impact or not) & 1 & 0 & 1 & 1 & 0 & 0 & 0 & 0 \\
\hline
\end{tabular}

Note: when the rainfall within 12 hours is more than $5 \mathrm{~mm}$ (08:00-20:00) or the rainfall within 24 hours is greater than $10 \mathrm{~mm}$, the larger value shall be applied. 


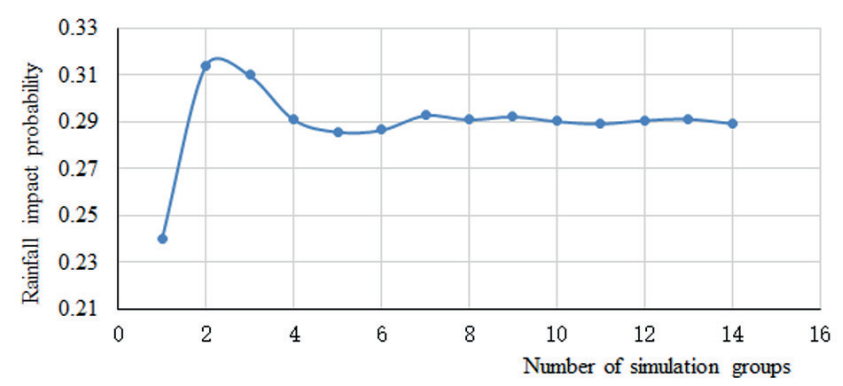

Fig. 3 Rainfall probability convergence curve

\subsection{Uncertainty analysis method}

Due to the uncertainty of rainfall, its impact on construction timescale is also uncertain. The risk caused by the uncertainty of rainfall is mainly estimated by the probability of rainfall. Specifically, it is mainly to calculate the probability that the actual construction timescale exceeds the planned one.

If the planned timescale is $T_{p}$, the absolute timescale is $T_{a}$, and the time (days) affected by the rainfall is $T_{m}$, then the risk that the project cannot be completed as planned could be expressed as:

$P_{r}=P\left(T_{m}+T_{a}>T_{p}\right)$.

According to the probability theory, whether the construction is affected by rainfall on any day in the schedule follows the (0-1) distribution of the parameter $p$, namely $X_{k} \sim(0-1)$, where $p$ is the probability that construction is affected by rainfall. Assume the timescale that includes the period affected by rainfall is $T$, therefore $T_{m} \sim B(T, p)$. In this paper, $P_{r}$ in Eq. (22) is determined by simulation test of $T$ in each month. Assume the number of days in the $i^{\text {th }}$ month is $T_{i}$, the construction schedule (days) that would be affected by the rainfall in the $i^{\text {th }}$ month is $\sum X_{i k} \sim B\left(T_{i}, p_{i}\right)$. According to the central-limit theorem, $\sum X_{i k}$ approximately follows the normal distribution, i.e., $\sum X_{i k} \sim N\left(\mu_{i}, \sigma_{i}^{2}\right)$, where:

$\mu_{i}=T_{i} p_{i}$,

$\sigma_{i}^{2}=T_{i} p_{i}\left(1-p_{i}\right)$

where

$\mu_{i}$ - the expected days affected by rainfall in the $i^{\text {th }}$ month

$\sigma_{i}^{2}$ - Variance of days affected by rainfall in the $i^{\text {th }}$ month
If the project has a schedule of $s$ months, the schedule (number of days) will be affected by the rainfall is $T_{m}=\sum\left(X_{1 k}+X_{2 k}+\ldots+X_{s k}\right)$, according to the additivity of the normal distribution, we can get:

$T_{m}=\sum\left(X_{1 k}+X_{2 k}+\ldots+X_{s k}\right) \sim N\left(\mu_{s}, \sigma_{s}^{2}\right)$

where:

$$
\begin{aligned}
\mu_{s} & =\mu_{s 1}+\mu_{s 2}+\ldots+\mu_{s s}=T_{1} p_{1}+T_{2} p_{2}+\ldots \\
& +T_{s} p_{s} \approx T_{0}\left(p_{1}+p_{2}+\ldots+p_{s}\right), \\
\sigma_{s}^{2} & =\sigma_{s 1}^{2}+\sigma_{s 2}^{2}+\ldots+\sigma_{s s}^{2}= \\
& T_{1} p_{1}\left(1-p_{1}\right)+T_{2} p_{2}\left(1-p_{2}\right)+\ldots+T_{s} p_{s}\left(1-p_{s}\right) \approx \\
& T_{0}\left[p_{1}+p_{2}+\ldots+p_{s}-\left(p_{1}^{2}+p_{2}^{2}+\ldots+p_{s}^{2}\right)\right] .
\end{aligned}
$$

Among Eq. (25), Eq. (26) and Eq. (27), $\mu_{s}, \mu_{s 1}, \mu_{s 2}, \mu_{s s}$ are the expected days that affected by rainfall in the first month, the second month, the $s^{\text {th }}$ month among $s$ months; $\sigma_{s}^{2}, \sigma_{s 1}^{2}, \sigma_{s 2}^{2}, \sigma_{s s}^{2}$ are the variance of days that affected by rainfall in the first month, the second month, the $s^{\text {th }}$ month among $s$ months; $p_{1}, p_{2}, \ldots, p_{s}$ are the probabilities that affected by rainfall in the first month, the second month, ..., the $s^{\text {th }}$ month; $T_{1}, T_{2}, \ldots, T_{s}$ are the number of days in the first month, the second month, ..., the $s^{\text {th }}$ month, which could be approximately estimated as 30 days.

$T_{0}$ - The average number of days in each month, which could be approximately estimated as 30 days.

According to Eq. (22), we can get:

$P_{r}=1-P\left(T_{m} \leq T_{p}-T_{a}\right)=1-\Phi\left(\left(\left(T_{p}-T_{a}\right)-\mu_{s}\right) / \sigma_{s}\right)$.

\subsection{Calculation and evaluation of risks}

Regarding to the project mentioned in Section 2, Monte Carlo simulation method is applied for the calculation (Table 5). It could be observed from Table 5 that the rainfall had a great impact on the construction process and the degree of impact was fluctuated in different seasons. When the planned schedule is 1 year (365 days), the histogram distribution of the days that affected by rainfall and its fitted curve are shown as Fig. 4. The fitted distribution

\begin{tabular}{|c|c|c|c|c|c|c|c|c|c|c|c|c|}
\hline Item & Jan. & Feb. & Mar. & Apr. & May & Jun. & Jul. & Aug. & Sep. & Oct. & Nov. & Dec. \\
\hline Number of days in the month $(d)$ & 31 & 28 & 31 & 30 & 31 & 30 & 31 & 31 & 30 & 31 & 30 & 31 \\
\hline Rain probability & 0.07 & 0.04 & 0.13 & 0.23 & 0.39 & 0.43 & 0.36 & 0.29 & 0.17 & 0.06 & 0.07 & 0.06 \\
\hline Influence days $(d)$ & 2 & 1 & 4 & 7 & 12 & 13 & 11 & 9 & 5 & 2 & 2 & 2 \\
\hline
\end{tabular}
curve of the days that affected by rainfall basically follows the normal distribution, which is consistent with the previous analysis.

Table 5 Summary of calculation results 


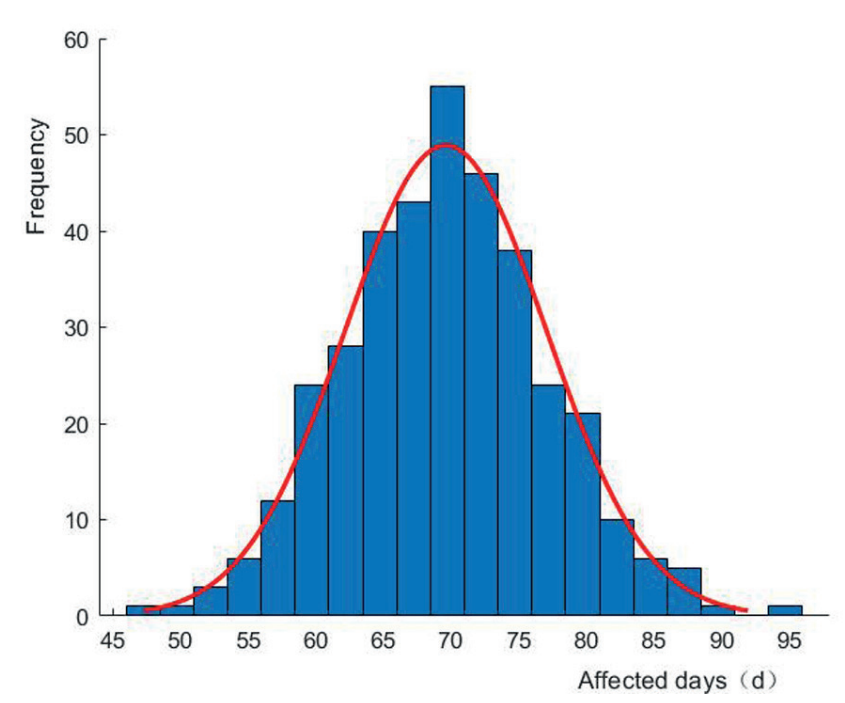

Fig. 4 Distribution days affected by rainfall

In the case of which the absolute schedule is 118 days and the planned schedule is 150 days, if the start date is set as January 1, June 1, and July 1, respectively, the corresponding completion risks are calculated as $6.95 \%, 91.92 \%$ and $23.27 \%$ through the uncertainty analysis method. Clearly, the maximum deviation of such risk exceeds $80 \%$, which indicates that the completion risk would become quite different due to the distinctions in start dates, and the corresponding measures ought to be implemented. These measures include adding construction manpower, adequately selecting the construction machinery and equipment, appropriate deployment of construction teams and applying advanced construction technologies. For instance, if the analysis indicates the risk of on time completion is high, the project manager should deploy additional construction resources in advance, extend the operation time and optimize the construction technologies to rectify the construction schedule. When preparing planned schedules during bidding, the impact of rainfall on construction process needs to be evaluated, and strategies to cope with such uncertainties should be formulated. Through the quantitative analysis of schedule risks, it can provide references for engineering decision-making.

\section{Conclusions}

Based on the schedule-cost assumption theory, a mathematical model that takes account of the cost, the number of teams and the cyclical footage was established. Some new uncertainty analysis methods for construction timescale are proposed to better illustrate the sewage pipe network optimization theory and the risk analysis theory. The main conclusions are as follows:
(1) For the sewage pipe network project, a mathematical model that takes account of the cost, the number of teams and the cyclical footage can be established; the cyclical footage can be regarded as a relatively constant number, and the cost can be regarded as a function of the number of teams.

(2) In the case of insufficient meteorological data, Monte Carlo simulation and uncertainty analysis methods can be used to evaluate the impact of rainfall on the construction schedule and quantitatively obtain the corresponding probability of such risks.

(3) The rainfall has a great impact on construction and the impact fluctuates significantly with seasons changing; the analysis showed that the distribution curve of days that affected by rainfall basically follows the normal distribution.

(4) The completion risk will tremendously vary if the project starts up on different dates, the maximum deviation of such risk exceeds $80 \%$. The risk factor of rainfall needs to be considered and the corresponding strategies and measures should be made to deal with these risks.

For other construction projects of sewage pipe network, the mathematical model established in the paper can be used to predict the optimal number of teams and the optimal construction timescale of the project, therefore to save the total construction cost. The calculation method introduced in this paper can be used to quantitatively analyze the uncertain risk that caused by the rainfall as well, so that, to evaluate the impact of rainfall on the construction schedule and obtain the probability of risks, so as to adopt corresponding measures. Moreover, the availability of the methodologies that proposed in this paper can be verified and tracked in specific engineering projects, so as to be optimized and improved. This research may be applied in highway, civil and hydraulic engineering projects to propose corresponding solutions in different circumstances.

\section{Acknowledgement}

The project presented in this article is supported by Jiangsu Provincial Department of Housing and UrbanRural Development, 2019 Provincial Construction System Science and Technology Project (Grant No. 2019ZD084) and 2020 School-level Scientific Research Project of Jiangsu Vocational Institute of Architectural Technology (Grant No. JYJBZX20-07). 


\section{References}

[1] Lin, M. "Research on Optimizing the Reconstruction of Urban Villages in Guangzhou Based on Interest Game", MSc Thesis, Guangdong University of Technology, 2019. (in Chinese)

[2] Yang, Z., Hu, P., Liu, Z. "Village-City Symbiosis: Research on Urban Village Renovation in Shenzhen", Design Community, 3, pp. 81-86, 2020. (in Chinese)

[3] Gao, H., Chai, S. "Project Cost and Time Limit Based on Fuzzy Mathematics Theory", Journal of Wut (Information \& Management Engineering), 37(6), pp. 786-794, 2015. (in Chinese)

[4] Yang, F. "Project based on genetic algorithm period-cost optimization model for analysis", MSc Thesis, Zhengzhou University, 2014. (in Chinese)

[5] Ma, G., Zhang, L. "Construction Project Schedule Optimization Based on Improved Genetic Algorithm", Journal of Civil Engineering and Management, 36(5), pp. 1-6, 2019. (in Chinese)

[6] Sarkar, D. "Hybrid approach for resource optimization and management of bridge projects using bootstrap technique and genetic algorithm", International Journal of Construction Management, 18(3), pp. 207-220, 2018.

https://doi.org/10.1080/15623599.2017.1315526

[7] Amiri, M. J. T., Haghighi, F. R., Eshtehardian, E., Abessi, O. "Multiproject Time-cost Optimization in Critical Chain with Resource Constraints", KSCE Journal of Civil Engineering, 22(10), pp. 3738$3752,2018$.

https://doi.org/10.1007/s12205-017-0691-x

[8] Heravi, G., Moridi, S. "Resource-Constrained Time-Cost Tradeoff for Repetitive Construction Projects", KSCE Journal of Civil Engineering, 23(8), pp. 3265-3274, 2019. https://doi.org/10.1007/s12205-019-0151-x

[9] Safavi, H., Geranmehr, M. A. "Optimization of sewer networks using the mixed-integer linear programming", Urban Water Journal, 14(5), pp. 452-459, 2017. https://doi.org/10.1080/1573062X.2016.1176222

[10] Haghighi, A., Bakhshipour, A. E. "Optimization of sewer networks using an adaptive genetic algorithm", Water Resources Management, 26(12), pp. 3441-3456, 2012.

https://doi.org/10.1007/s11269-012-0084-3

[11] Tian, J., Cheng, J., Gong, Y. "Study on optimization design method of urban sewage transportation system", Water \& Wastewater Engineering, 43(4), pp. 115-121, 2017. (in Chinese)

[12] Wang, G., Xie, J., Zhang, J. "Optimization of water supply network based on improved ant colony algorithm", Journal of Northwest A \& F University (Natural Science Edition), 42(1), pp. 228-234, 2014. (in Chinese)

[13] Wols, B. A., Vogelaar, A., Moerman, A., Raterman, B. "Effects of weather conditions on drinking water distribution pipe failures in the Netherlands", Water Supply, 19(2), pp. 404-416, 2019. https://doi.org/10.2166/ws.2018.085

[14] Robles-Velasco, A., Muñuzuri, J., Onieva, L., Cortés, P. "An evolutionary fuzzy system to support the replacement policy in water supply networks: The ranking of pipes according to their failure risk", Applied Soft Computing, 111, Article No. 107731, 2021. https://doi.org/10.1016/j.asoc.2021.107731
[15] Robles-Velasco, A., Ramos-Salgado, C., Muñuzuri, J., Cortés, P. "Artificial Neural Networks to Forecast Failures in Water Supply Pipes", Sustainability, 13(15), Article No. 8226, 2021. https://doi.org/10.3390/su13158226

[16] Reda, R., Carr, R. I. "Time-Cost Trade-Off Among Related Activities", Journal of Construction Engineering and Management, 115(3), pp. 475-486, 1989. https://doi.org/10.1061/(ASCE)0733-9364(1989)115:3(475)

[17] Liu, W. "Study on Optimization of Construction Schedule Based on Lean Six Sigma Management", PhD Theis, Xi'an University of Architecture and Technology, 2015. (in Chinese)

[18] Gould, F. E. "Managing the construction process: estimating, scheduling and project control", Prentice Hall, NJ, USA, 2002.

[19] Zhou, L., Ma, J. "Modeling and Analysis of Bayesian Network in Engineering Project Schedule Risk Management", Journal of Engineering Management, 26(1), pp. 69-74, 2012. (in Chinese)

[20] Wang, Z., Liu, J., Ding, J. "Cost-risk analysis of earth dam construction with considerations of schedule uncertainty", Journal of Hydroelectric Engineering, 30(5), pp. 229-233, 2011. (in Chinese)

[21] Tian, B., Huang, J., Chen, H. "The BN-based risk analysis of railway construction close to existing line", Journal of Engineering Management, 15(8), pp. 2163-2171, 2018. (in Chinese)

[22] Jiang, X., Li, W., Hu, W. "A Risk Assessment of Hydraulic Engineering Operation Based on SPA-Cloud Model", China Rural Water and Hydropower, (11), pp. 145-150, 2019. (in Chinese)

[23] Yuan, H., Zhang, W., You, J. "Assessment of Bridge Construction Safety Risk based on Improved Cloud Model", Journal of Engineering Studies, 10(6), pp. 600-606, 2018. (in Chinese)

[24] Pietrucha-Urbanik, K., Tchórzewska-Cieślak, B., Eid, M. "A Case Study in View of Developing Predictive Models for Water Supply System Management", Energies, 14(11), Article No. 3305, 2021. https://doi.org/10.3390/en14113305

[25] Tchórzewska-Cieślak, B., Pietrucha-Urbanik, K., Eid, M. "Functional Safety Concept to Support Hazard Assessment and Risk Management in Water-Supply Systems", Energies, 14(4), Article No. 947, 2021. https://doi.org/10.3390/en14040947

[26] Kwak, Y. H., Ingall, L. "Exploring Monte Carlo Simulation Application for Project Management", Risk Management, 9, pp. 44-57, 2007. https://oi.org/10.1057/palgrave.rm.8250017

[27] Ökmen, Ö., Öztaş, A. "Construction Project Network Evaluation with Correlated Schedule Risk Analysis Model", Journal of Construction Engineering and Management, 134(1), pp. 49-63, 2008. https://doi.org/10.1061/(ASCE)0733-9364(2008)134:1(49)

[28] Wang, M., Zhou, Y., Zhao, S. "The Method for Deriving Rainfall Depth Formula", Journal of Shenyang Jianzhu University (Natural Science), 24(2), pp. 274-277, 2008. (in Chinese) 